\title{
Study Chair Name
}

National Cancer Institute

\section{Source}

National Cancer Institute. Study Chair Name. NCI Thesaurus. Code C129944.

The name of the person who has overall responsibility for the technical conduct of a study, as well as for the interpretation, analysis, documentation and reporting of results, and represents the single point of study control. (FDA) 